\title{
Effectiveness of Fibrin Glue for Preventing Postoperative Extradural Fluid Leakage
}

\author{
Tetsuyuki Yoshimoto, Yutaka SAWAMURA, \\ Kiyohiro HoukIN, and Hiroshi ABE
}

Department of Neurosurgery, Hokkaido University School of Medicine, Sapporo

\begin{abstract}
Cerebrospinal fluid (CSF) leakage through dural sutures after craniotomy increases the risk of complications such as persistent CSF fistulas, meningitis, and subcutaneous, graft bone, or epidural infections. The effectiveness of fibrin glue for preventing CSF leakage through dural closure was investigated in 183 patients who underwent frontotemporal craniotomy for unruptured aneurysm. Fibrin glue was used in 138 patients, but not in the other 45. Computed tomography was used to evaluate postoperative extradural fluid collection as a minimal volume of low-density area. Postoperative computed tomography demonstrated transient increases in extradural fluid collection in 55 patients. However, none of these patients received a second surgery for dural repair. Fluid collection occurred in 19 of 45 patients (42\%) in whom fibrin glue was not used, and in 36 of 138 patients $(26 \%)$ in whom fibrin glue was used. The fibrin sealant on the dural suture was a significant factor in reducing the incidence of the fluid leakage ( $p<\mathbf{0 . 0 5}$, chi-square test). Fibrin glue is a useful surgical tool for the prevention of postoperative extradural fluid collection through the dural sutures.
\end{abstract}

Key words: cerebrospinal fluid, dura mater, fibrin glue, craniotomy

\section{Introduction}

Cerebrospinal fluid (CSF) collection outside the dura mater is often detected by postoperative neuroimaging after intracranial surgery despite use of conventional water-tight closure techniques. Epidural and/ or subcutaneous fluid collections at the site of a craniotomy are usually asymptomatic and spontaneously absorbed. However, such leakage and collection increases the potential risk of persistent CSF fistulas, meningitis, subcutaneous, graft bone, or epidural infections, and subdural hematoma. ${ }^{1,2}$

Fibrin glue can be used for hemostasis, as a bioadhesive, and fixative of injured tissue. The advantage of fibrin glue is the composition of human plasma protein which may generate fewer immune reactions compared to other surgical materials such as gelatin sponges, oxidized cellulose, or microfibrillar collagen. Therefore, fibrin glue has recently been used in various neurosurgical procedures ${ }^{1-13)}$ including cranial bone plasty, nerve suture, hemostasis on the dural sinus, as a supporter of inserted materials,

Received May 26, 1997; Accepted September 30, 1997 and especially for the prevention of CSF leakage through dural sutures. Most neurosurgeons acknowledge the efficiency of fibrin glue in sealing fluid leakage, but the accuracy of this assumption remains to be proven. This study analyzed the effect of fibrin sealant on the dural closure to determine the effectiveness in reducing CSF leakage after craniotomy for unruptured aneurysm.

\section{Materials and Methods}

The study included 183 patients, 108 females and 75 males, with a mean age of 60 years, who underwent craniotomy for unruptured aneurysm at the Department of Neurosurgery, Hokkaido University Hospital and its affiliated two hospitals between 1990 and 1995 (Table 1). The aneurysms were located at the anterior communicating artery (AcomA) (37 aneurysms), at the middle cerebral artery (85 aneurysms), at the internal carotid artery (74 aneurysms), and at the basilar artery ( 3 aneurysms). Fourteen patients had two aneurysms and one patient had three aneurysms. To simplify the assessment, we selected patients who underwent only routine craniotomies such as frontotemporal or 
Table 1 Case summary

\begin{tabular}{|c|c|c|c|c|c|c|c|}
\hline \multirow{2}{*}{ Fibrin glue } & \multirow{2}{*}{$\begin{array}{c}\text { No. of } \\
\text { patients }\end{array}$} & \multirow{2}{*}{$\begin{array}{c}\text { Mean age } \\
\text { (yrs) }\end{array}$} & \multirow{2}{*}{$\begin{array}{c}\text { Sex } \\
\text { (female/male) }\end{array}$} & \multicolumn{4}{|c|}{ Site of aneurysm } \\
\hline & & & & $A \operatorname{com} A$ & $\mathrm{MCA}$ & ICA & $\mathrm{BA}$ \\
\hline Used & 138 & 60.0 & $84 / 54$ & 27 & 69 & 53 & 2 \\
\hline Not used & 45 & 59.2 & $24 / 21$ & 10 & 16 & 21 & 1 \\
\hline Total & 183 & 60.0 & $108 / 75$ & 37 & 85 & 74 & 3 \\
\hline
\end{tabular}

AcomA: anterior communicating artery, BA: basilar artery, ICA: internal carotid artery, MCA: middle cerebral artery.

bifrontal craniotomy for unruptured aneurysms. Unruptured aneurysms located at the anterior part of the circle of Willis were chosen because routine dural water-tight closure could be achieved. The dural opening was almost uniform and the closure was fine and water-tight. The study did not include patients who had a ventricular or a cisternal drainage passing through the dura mater since patients with ruptured aneurysms were excluded. All patients had subcutaneous drainage for just one day after the operation.

Bolheal fibrin glue (Fujisawa Pharmaceutical Co., Tokyo) was used in 70 cases and Veriplast $P$ fibrin glue (Hoechst Japan, Tokyo) in 68 cases. These fibrin glues are produced from pooled human plasma and have a similar composition. Briefly, the dried protein of Bolheal is heat-treated for 144 hours at $65^{\circ} \mathrm{C}$ and the aqueous protein solution of Veriplast for 10 hours at $60^{\circ} \mathrm{C}$. The glues are negative for transmissible virus infections including human immunodeficiency virus, and hepatitis $\mathrm{B} / \mathrm{C}$ virus. The glue consists of two solutions: one containing 80 $\mathrm{mg} / \mathrm{ml}$ human fibrinogen, $75 \mathrm{U} / \mathrm{ml}$ human factor VIII, and $100 \mathrm{KIE} / \mathrm{ml}$ bovine aprotinin, and the other $250 \mathrm{U} / \mathrm{ml}$ human thrombin, and $5.9 \mathrm{mg} / \mathrm{ml} \mathrm{CaCl}_{2}$.

Fibrin glue was applied as an adjunct procedure to conventional dural sutures in 138 patients, but not for the other 45 patients. Ordinary osteoplastic frontotemporal craniotomies and dural incision were carried out to treat the unruptured aneurysms in 163 patients, but 20 patients with AcomA aneurysm underwent bifrontal craniotomies. The surgeons attempted water-tight closure of the dura mater with 4-0 silk strings. After absence of CSF leakage was ascertained, fibrin glue $\left(2 \mathrm{ml} / 10 \mathrm{~cm}^{2}\right)$ was applied to the dural surface. The method of using sterile syringes to mix the two solutions of fibrin glue separately on the dura mater was used in the period between 1990 and 1993, and the glue was applied by the spray method from 1994 to $1995 .^{8 !}$

Epidural and subcutaneous fluid collections was assessed by computed tomography (CT) scan, which first taken within a week of surgery, then repeated at least every 4 weeks. Excluding apparent CT findings indicating hematoma, an increase of low-density area, even slightly, in the epidural or the subcutaneous space was regarded as "fluid collection," although it was impossible to determine whether the fluid was CSF. To avoid ambiguity, the evaluation was strictly performed, so even a minimum small low density in the subcutaneous and epidural space on the CT scan was considered fluid collection. Results were analyzed using the chi-square test and Mantel-Haenszel odds ratio.

\section{Results}

Postoperative CT revealed extradural fluid collection in 55 patients (Table 2). Fluid collection occurred in 19 of 45 patients ( $42 \%$ ) in whom fibrin glue was not used and in 36 of 138 patients $(26 \%)$ in whom fibrin glue was applied. The fibrin sealant on the dural suture was a significant factor in reducing the incidence of the fluid leakage $(p<0.05$, chisquare test). Mantel-Haenszel odds ratio indicated that the incidence of fluid collection was increased 0.474 times by addition of the fibrin glue to the dural suture. The fluid collections were detected 6 to 28 days (mean 13.4 days) after the surgery. Fluid collections were seen in the subcutaneous space in 21 patients, in the epidural space in 20 , and in both in 14. There was no significant difference in the sites of fluid collection between patients in whom fibrin glue was used and those in whom fibrin glue was not used (Table 2). There were also no significant influences of patient age or site of the aneurysm (data not shown).

The fluid collections detected on CT were transient in all patients. No patient required second surgery for dural repair due to CSF leakage, and none showed signs of infection, including meningitis. No adverse effects related to the fibrin glue, such as systemic anaphylaxis or chronic inflammation at the site of application, were detected. 
Table 2 Incidence of transient extradural fluid collection after craniotomy with or without application of fibrin glue

\begin{tabular}{|c|c|c|c|c|c|}
\hline \multirow{3}{*}{ Fibrin glue } & \multicolumn{4}{|c|}{ Fluid collection } & \multirow{3}{*}{ No } \\
\hline & \multicolumn{4}{|c|}{ Yes } & \\
\hline & Subcutaneous & Epidural & Combined & Total & \\
\hline Used & 12 & 15 & 9 & $36(26.1 \%]^{*}$ & $102(73.9 \%)$ \\
\hline Not used & 9 & 5 & 5 & $19(42.2 \%]^{*}$ & $26(57.8 \%)$ \\
\hline Total & 21 & 20 & 14 & 55 (30.1\%] & $128(69.9 \%)$ \\
\hline
\end{tabular}

${ }^{*}$ Chi-square test, $\mathrm{p}<0.05$.

\section{Discussion}

This study revealed a high frequency of CSF collection after routine dural closure despite the use of fibrin glue. However, our evaluation was very strict in selecting low-density areas outside the dura mater on CT. The true incidence of fluid collection in the subcutaneous space, excluding only epidural fluid collection, was $21 / 138(15 \%)$ of the patients in whom fibrin glue was used and $14 / 45$ (31\%) of the patients without use of fibrin glue. This lower volume reflects the sealant effect of the fibrin glue.

We often observed postoperative subcutaneous or epidural fluid collections on CT, which were fortunately absorbed spontaneously. This fluid collection poses the risk of development of a CSF fistula that may finally require dural repair by a second craniotomy. This risk should be considered particularly in the postoperative course of surgery in the posterior fossa, the skull base, and difficult cases lasting for long periods. The use of fibrin glue as an adjunct to dural suture is endorsed to diminish the incidence of these minor neurosurgical complication, but the cost against benefit of its use should be taken into consideration for each patient. We think that complications have been decreasing since use of the spray method. The sealing effect of the spray method was previously proved to be highest in the methods for the application of fibrin glue. ${ }^{13)}$ Fibrin sealant applied by the spray method on a dural tear sustained a water pressure of over $80 \mathrm{~cm} \mathrm{H}_{2} \mathrm{O}$, which is far higher than the normal CSF pressure. ${ }^{13]}$

Present fibrin glues are manufactured from pooled human plasma. The heat-treatment process prevents transmissible virus infections. However, heat-tolerant proteins also exist and such transmissions may not be prevented in the future. Therefore, fibrin may need to be produced from self-pooled plasma.

\section{Acknowledgment}

We greatly thank for co-operation and assistance to Dr. Takeshi Kashiwaba and Miss Yukari Nagasaki of Kashiwaba Neurosurgical Hospital, Sapporo and Dr. Hisatoshi Saito and Miss Ritsuko Ohdera of Sapporo Azabu Neurosurgical Hospital, Sapporo.

\section{References}

1) Burres RP, Conley FR: Progressive neurosurgical dysfunction secondary to postoperative cervical pseudomeningocele in a C-4 quadriplegic. Case report. $J$ Neurosurg 48: 289-291, 1978

2) Eismont FJ, Wiesel SW, Rothman RH: Treatment of dural tears associated with spinal surgery. $J$ Bone Joint Surg Am 63A: 1132-1136, 1981

3) Ferrante L, Palatinsky E, Acqui M, Mastronardi L: Extradural extracranial repair for cerebrospinal otorrhea with human fibrin glue: Technical note. J Neurol Neurosurg Psychiatry 51: 1438-1440, 1988

4) Fujii T, Misumi S, Onoda K, Takeda F: Simple management of cerebrospinal fluid rhinorrhea after pituitary surgery. Surg Neurol 26: 345-348, 1986

5) Hasegawa H, Bitoh S, Obashi J, Maruno M: Closure of carotid cavernous fistulae by use of a fibrin adhesive system. Surg Neurol 24: 23-26, 1985

6) Renato S, David S, Dale F, Marcia B, Alan D, Luis OV: Experimental and clinical applications of fibrin glue. Plast Reconstr Surg 88: 1005-1015, 1991

7) Sawamura $Y$, Sudo $M$, Kato T, Ishii N, Abe H: [Absorption and formation of granuloma of fibrin glue applied on the human dura mater: Histological examination of specimens obtained by second craniotomy]. No Shinkei Geka Journal 4: 364-369, 1995 (Jpn, with English abstract)

8) Sawamura Y, Terasaka S: [Neurosurgical application of fibrin glue: Technical note for protection of cerebrospinal fluid-leakage and osteoplastic craniectomy]. Neurosurg Lett 4: 1025-1032, 1995 (Jpn)

9) Sawamura Y, Terasaka S, Ishii N, Tada M, Abe H: Osteoregenerative lateral suboccipital craniectomy using fibrin glue. Acta Neurochir (Wien) 139: 446-452, 1997 
10) Shaffrey CI, Spotnitz WD, Shaffrey ME, Jane JA: Neurosurgical applications of fibrin glue: Augmentation of dural closure in 134 patients. Neurosurgery 26: $207-210,1990$

11) Spetzler RF, Wilson CB: Management of recurrent CSF rhinorrhea of the middle and posterior fossa. $J$ Neurosurg 49: 393-397, 1978

12) Symon L, Pell MF: Cerebrospinal fluid rhinorrhea following acoustic neurinoma surgery. Technical note. J Neurosurg 74: 152-153, 1991

13) Terasaka S, Sawamura $Y$, Abe H: [Sealing effect of fibrin glue spray on the protection of cerebrospinalfluid leakage through the dura mata]. No Shinkei Geka 22: 1015-1019, 1994 (Jpn, with Eng abstract)

Address reprint requests to: T. Yoshimoto, M.D., Department of Neurosurgery, Hokkaido University School of Medicine, North-15, West-7, Kita-ku, Sapporo 060, Japan.

\section{Commentary}

Postoperative cerebrospinal fluid (CSF) leakage is a serious unsolved problem, especially after operations at the skull base. The authors have performed a valuable study by comparing the results in the group in which the dura was repaired with separate sutures and fibrin glue and those in the group in which only sutures were used for dural closure. The results speak in favor of using fibrin glue in addition to the suturing of the dura. The fact that the dural leakage occurred in $15 \%$ of cases in which the dura was sutured and the suture reinforced with fibrin glue, and in $31 \%$ of cases in which fibrin glue was not used in combination with the suturing of the dura at the end of surgery, is not surprising. Postoperative checking, with CT, of possible CSF accumulation epidurally is a good and acceptable method though it is difficult to be absolutely sure what is a pure fluid collection and what are low density residuals of a hematoma. It is also necessary to mention that one would expect higher water-sealing efficiency of fibrin glue than was established by this prospective study. The above mentioned data show the real value of the study, i.e. that we still do not have a $100 \%$ sure method to prevent any possible leakage of the CSF through the dura. Last but not least, an important question which is also discussed in this report concerns the heat tolerant proteins which most probably will in future modify fibrin glue in the sense that "the fibrin glue needs to be produced from self-pooled plasma."

Vinko V. DOLEnC, M.D. Department of Neurosurgery University Hospital Center
Ljubljana, Slovenia

This is an interesting paper by Yoshimoto et al. examining the effectiveness of fibrin glue in reinforcing dural closure after surgery. Although in the supratentorial compartment epidural CSF collection is common but seldom a threat to the patient, CSF leaks after posterior fossa surgery and skull base surgery are serious problems. I was impressed to see that the repair with the spray glue withstood a pressure of 80 $\mathrm{cm}$ water. The question remains as to what happens to the glue with the fibrinolytic effect of CSF of the days after the operation? In my experience, fibrin glue has rarely been helpful in preventing CSF leaks after surgery. I rely on other means of repair like dural grafts, the use of vascularized tissue rotation for closure. It would be interesting to see whether the fibrin glue is helpful in skull base and posterior fossa surgery for the prevention of CSF leaks.

Chandranath SEN, M.D. Department of Neurosurgery The Mount Sinai Medical Center New York, U.S.A.

This article provides useful information on the efficacy of fibrin glue to prevent postoperative cerebrospinal fluid (CSF) leakage. However, I wonder about the authors' result that extradural CSF collection was observed in $26 \%$ of 138 patients in whom fibrin glue was used. This frequency is surprisingly higher than that reported by Shaffrey et al. (ref. 10 of this article) earlier, when only $5 \%$ among 83 patients who underwent craniotomies were considered to have failed. The authors used fibrin glue for the patients who had no dural defect not only preoperatively but also during operation. In general, extradural CSF collection after craniotomy resolves conservatively without subsequent surgical procedures. Thus, one should be cautious in using fibrin glue as an adjunct to dural closure.

Katsuji SHIma, M.D.

Department of Neurosurgery

School of Medicine

National Defense Medical College

Saitama, Japan

In this study, Yoshimoto et al. used fibrin glue for preventing cerebrospinal fluid (CSF) leakage through dural closure in patients who underwent frontotemporal craniotomy for unruptured aneurysm. CSF leakage can be a cause of post-operative complication such as CSF fistula, meningitis, etc., as mentioned by the authors. So, ргеventing CSF leakage is one of the most important procedures in neurosurgical operations. Accordingly, use of fibrin glue is widely recommended for preventing CSF leakage. However, $15 \%$ in- 
cidence of subcutaneous fluid collection still seems high, so another sealant material or method such as arachnoid closure should be developed.

Nobuyuki YASUI, M.D.
Department of Surgical Neurology Research Institute for Brain and Blood Vessels-AKITA Akita, Japan 